\title{
東京のハシブトガラスの諸検測例 胃内容，腸内寄生虫所見
}

黒田長 久*

1969年 5 月27，28日に宮内庁で皇居内のハシブトガラス Corvus leraillantii japonensis 13 羽が採集され食性などの調査の御依頼を受けた。

これらはすべて午前中に採集された。以下検測の所見を記す。はに゙めに寄生虫を同定してい ただいた目黒寄生虫館市原醇郎氏に御礼を述べる。

\section{一 般 所 見}

採集されたのは，今 6 羽 (若鳥 1 または 2 羽), 古 7 羽 (若鳥 1 羽) で, これは皇居内の群 母集団からの無作意採集の結果，性比の均等が示された 1 例といえよう。ハシブトガラスの繁 殖鳥は皇居内や都内に広くなわばり分散しており，ねぐらだけを集団でとるが（年齢と共に少 くも繁殖期の独立性が高まる), 恐らく2 歳までの非繁殖鳥は群集会所に集まり, 皇居はその 中心の一つである。今回はすでに巣立期であったが， + 1 羽にまだ抱卵斑があった。これは皇 居内営巣のものと思われるが，そのほかは上記の非繁殖成鳥と考えられる。しかし，今早各 1 羽は明らかに当嵗若鳥でファブリシウス垔が残っていた。生殖器からみて他の今 1 羽女若鳥と 思われた。

1. 外部測定と体重

測定は，体重，全長，翼開張，翼長（自然長），尾長，嘴峯，跗路について行なった。嘴高 为地方個体群の比較に必要で, 体長（肩から排泄孔）も腸長などに対する体軀の基準測定とし て有用だが今回は省略した（第 1 表）。

表に示すように, 測定上性差がはっきり認められた。そこで, “性差指数” sexual index を 考えてみよう。これは，大きい方の性の測定值に対する小さい方の性の測定值の\%とし，一般 的な今>早の場合は正(+)，反対の場合は負(ーとして取扱うこととする。すなわち

性差指数 sexual index (S.I.) $=\frac{\text { 小さい性の測定值 }}{\text { 大きい性の測定值 }}$

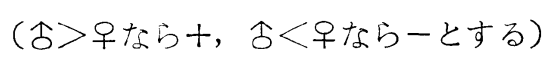

となる。今回のハシブトガラスについて測定平均值 $(\mathrm{mm}, \mathrm{g})$ は：体重 ㅇ 713.3/ 万7802.0, S.I. 88.94\%，全長우560.8/令588.0, S.I. 95.37\%，翼開張 우1021,6/令1080.0, S.I. 94. $59 \%$, 翼長우342.0/令357.4, S.I. 95.69\%，嘴峯우62.1/令 68.3, S.I. 90.92\%，跗蹠早

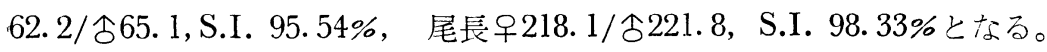

*山階鳥類研究所 $(150)$ 東京都沿谷区南平台 $8-20$ 
Table 1. Measurements of Corvus levaillantii japonensis of Tokyo, obtained in May, 1969

\begin{tabular}{|c|c|c|c|c|c|c|c|c|}
\hline $\begin{array}{l}\text { Specimen } \\
\text { No. }\end{array}$ & $\begin{array}{l}\text { Sex, } \\
\text { age }\end{array}$ & $\begin{array}{l}\text { Body } \\
\text { Weight }\end{array}$ & $\begin{array}{r}\text { Total } \\
\text { length }\end{array}$ & $\begin{array}{l}\text { Wing } \\
\text { span }\end{array}$ & $\begin{array}{c}\text { Wing } \\
\text { (Natural) }\end{array}$ & $\begin{array}{c}\text { Culmen } \\
\text { (Exposed) }\end{array}$ & Tarsus & Tail \\
\hline 9 & \$ ad. & $800^{(\mathrm{g})}$ & $\begin{array}{c}(\mathrm{mm}) \\
600\end{array}$ & $\begin{array}{c}(\mathrm{mm}) \\
1,090\end{array}$ & $\begin{array}{c}(\mathrm{mm}) \\
367\end{array}$ & $(\underset{67}{\mathrm{~mm}})$ & $(\underset{64}{\mathrm{~mm}})$ & $\begin{array}{l}(\mathrm{mm}) \\
238\end{array}$ \\
\hline 5 & 今 ad. & 850 & 560 & 1,080 & 360 & 71 & 64.5 & 224 \\
\hline 7 & के ad. & 800 & 600 & 1,100 & 360.1 & 68.5 & 64 & 230 \\
\hline 10 & o ad. & 760 & 590 & 1,070 & 350 & 68 & 66 & 220 \\
\hline 13 & o ad. & 800 & 590 & 1,060 & 350 & 67 & 67 & 217 \\
\hline Av. & $\begin{array}{l}5 \text { 令令 } \\
\text { ad. }\end{array}$ & 802.0 & 588.0 & $1,080.0$ & 357.4 & 68.3 & 65.1 & 221.8 \\
\hline $2^{*}$ & o juv. & 750 & 578 & 1,050 & 340 & 66 & 63 & 215 \\
\hline 1 & 우 $\mathrm{ad}$. & 700 & 580 & 1,060 & 344 & 67 & 64 & 220 \\
\hline 3 & 우 $\mathrm{ad}$. & 750 & 560 & 1,010 & 333 & 64.5 & 64 & 220 \\
\hline 4 & 우 $\mathrm{ad}$. & 750 & 540 & 1,040 & 345 & 65 & 62 & 220 \\
\hline 6 & 우 ad. & 750 & 560 & 1,020 & 335 & 62.5 & 63 & 214 \\
\hline 8 & 우 ad. & 650 & 545 & 1,020 & 340 & 60 & 60 & 210 \\
\hline $12^{+}$ & 우 ad. & 680 & 580 & 980 & 355 & 63.5 & 60 & 225 \\
\hline Av. & $\begin{array}{l}6 \text { 우 우 } \\
\text { ad. }\end{array}$ & 713.5 & 560.8 & $1,021.6$ & 342.0 & 63.7 & 62.5 & 218.1 \\
\hline $11 *$ & 우 juv. & 690 & 575 & 1,025 & 340 & 66 & 62 & 215 \\
\hline \multirow{3}{*}{6 令令 } & Range & $\begin{array}{l}750 \\
? \\
850\end{array}$ & $\overbrace{600}^{560}$ & $\begin{array}{l}1,050 \\
\text { ?, } 100\end{array}$ & $\begin{array}{c}340 \\
?_{367}\end{array}$ & $\begin{array}{c}66 \\
2 \\
71\end{array}$ & $\begin{array}{c}63 \\
67\end{array}$ & $\begin{array}{c}215 \\
2 \\
238\end{array}$ \\
\hline & Mean & $(793.3)$ & $(586.3)$ & $(1,076.7)$ & $(354.5)$ & $(67.9)$ & $(64.8)$ & $(224.0)$ \\
\hline & $\begin{array}{c}\text { S.D. } \\
\text { S.E. } \\
\text { G.V. }(\%)\end{array}$ & $\begin{array}{r} \pm 35.6 \\
\pm 14.4 \\
4.48\end{array}$ & $\begin{array}{r} \pm 15.3 \\
\pm 6.2 \\
2.69\end{array}$ & $\begin{array}{r} \pm 19.0 \\
\pm 7.7 \\
1.76\end{array}$ & $\begin{array}{r} \pm 9.7 \\
\pm 3.9 \\
2.73\end{array}$ & $\begin{array}{r} \pm 1.7 \\
\pm 0.69 \\
2.50\end{array}$ & $\begin{array}{r} \pm 1.5 \\
\pm 0.60 \\
2.31\end{array}$ & $\begin{array}{r} \pm 9.7 \\
\pm 3.7 \\
4.33\end{array}$ \\
\hline \multirow{5}{*}{7 우 우 } & Range & $\begin{array}{c}650 \\
? \\
750\end{array}$ & $\begin{array}{c}540 \\
? \\
580\end{array}$ & $\begin{array}{c}980 \\
\text { ? } \\
1,060\end{array}$ & $\begin{array}{c}333 \\
? \\
355\end{array}$ & $\begin{array}{c}62.5 \\
? \\
67\end{array}$ & $\begin{array}{c}60 \\
? \\
64\end{array}$ & $\begin{array}{c}210 \\
? \\
225\end{array}$ \\
\hline & Mean & $(710.0)$ & $(562.9)$ & $(1,021.4)$ & $(341.7)$ & $(64.1)$ & $(62.1)$ & $(217.7)$ \\
\hline & S.D. & \pm 39.7 & \pm 16.3 & \pm 24.8 & \pm 7.3 & \pm 2.3 & \pm 1.7 & \pm 5.0 \\
\hline & S.E. & \pm 14.9 & $\pm \quad 6.2$ & \pm 9.3 & \pm 2.7 & \pm 0.88 & \pm 0.64 & \pm 1.9 \\
\hline & G.V.(\%) & 5.59 & 2.89 & 2.42 & 2.13 & 3.58 & 2.73 & 2.29 \\
\hline \multicolumn{2}{|c|}{$\begin{array}{l}\text { Average 'sexual } \\
\text { index' } \%\end{array}$} & +88.94 & +95.37 & +94.59 & +95.69 & +90.92 & +95.54 & +98.33 \\
\hline
\end{tabular}

* Still having Bulsa of Fabricius. + With incubation patch. Others are mostly non-breeding subadults (of 2 nd year). No. 13 had testes as small as in No. 2. Cf. text as for 'sexual index'.

次に,この性差指数の意義について一考しておく。鳥類では今の大型なことが多いが, ハシブ トガラスの繁殖習性をみると, 古のみが抱卵し, その間占は広くなわばり内の慨探しに飛び回 り貯蔵し, 雌が巣に静止している間, 今の運動量従って消費エネルギーは非常に大きく, 雛が. 


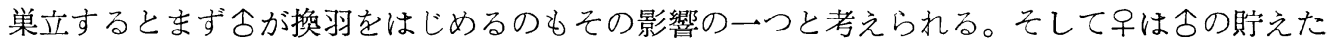
もの，近くに運んだものを食べ体力をあまり消費しない。鳥類の今の大型化には今の求愛にお けるエネルギーの多用の効果も働くが，羽色に性差のないカラスではむしろ，このような繁殖 分業が原因と思われる。エネルギ一の多用と体の大型化の関連は生理的に考察する必要があ る。そして，S.I. はこれらの一つの尺度となる。

ただし，性的分業のうち何がどの部分の測定に強く作用しているかについて検討せ齐ばなら ない。例えば，空中歌の習性のあるヒバリでは翼長（尾長も関連）にそれが反映する。また， 部分によって S.I. は正または負で混る場合があろう。タカでは雄が飭を運ぶが S.I. は負(早 が大）である。これは慨種の選択の幅を広める（S.I. が正でもよい筈だが）とか，そのほかの 要因があろう(例忘ば，小形の雄が比較的捕獲容易な小さい獲物を回数多く運ぶなど）。

なお，ファブリシウス囊の残存する当歳若鳥の今は各測定で最小でむったが，中ではほぼ平 均またはそれ以上であった。

2. 内部検測

体内の検測は, 生殖器, 脂肪, ファブリシウス囊, 砂囊, 腸, 1 羽について肝臓重, 胸筋,

Table 2. Gonad size and fat condition in collected examples

\begin{tabular}{|c|c|c|c|c|c|}
\hline $\begin{array}{l}\text { Specimen } \\
\text { No. }\end{array}$ & $\begin{array}{l}\text { Sex, } \\
\text { age }\end{array}$ & \multicolumn{3}{|c|}{ Gonad } & Fat \\
\hline \multirow{3}{*}{9} & \multirow{3}{*}{$\hat{o}$ ad. } & \multicolumn{2}{|c|}{ Testes } & \multirow[b]{2}{*}{ Shape } & \multirow{3}{*}{ Litîle } \\
\hline & & $\begin{array}{l}\text { Left } \\
(\mathrm{mm})\end{array}$ & $\begin{array}{l}\text { Right } \\
(\mathrm{mm})\end{array}$ & & \\
\hline & & $7 \times 5$ & $7 \times 5$ & Cubic & \\
\hline 5 & $\hat{o}$ ad. & $5 \times 3$ & $5 \times 3$ & " & Almost none \\
\hline 7 & $\hat{\circ}$ ad. & $9 \times 5$ & $8 \times 5$ & " & - \\
\hline 10 & $\hat{\delta}$ ad. & $7 \times 5$ & $8 \times 4$ & " & Almost none \\
\hline 13 & $\hat{o}$ ad. & $5.5 \times 2.5$ & $5 \times 3.5$ & Slender & A little \\
\hline $2 *$ & 立 juv. & $5 \times 2$ & $5 \times 2$ & " & A good amount \\
\hline \multirow{2}{*}{1} & \multirow{2}{*}{ 우 ad. } & \multicolumn{2}{|c|}{$\begin{array}{l}\text { Length of ovary } \\
(\mathrm{mm})\end{array}$} & $\begin{array}{l}\text { Large } \\
\text { follicles and } \\
\text { diameter }(\mathrm{mm})\end{array}$ & \multirow{2}{*}{ None } \\
\hline & & \multicolumn{3}{|r|}{ None } & \\
\hline 3 & 우 ad. & \multicolumn{2}{|l|}{-} & - & Very little \\
\hline 4 & 우 $\mathrm{ad}$. & 14 & \multicolumn{2}{|r|}{$\begin{array}{l}\text { Several, } \\
\max .4 \mathrm{~mm}\end{array}$} & $\begin{array}{l}\text { A little solid fat } \\
\text { in the belley }\end{array}$ \\
\hline 6 & 우 $\mathrm{ad}$. & 9 & \multicolumn{2}{|r|}{ No large follicle } & " \\
\hline 8 & 우 ad. & 12 & \multicolumn{2}{|r|}{3 follicles of $2 \mathrm{~mm}$} & None \\
\hline $12^{+}$ & 우 $\mathrm{ad}$. & $16 \times 9($ width $)$ & \multicolumn{2}{|r|}{3 follicles of $3 \mathrm{~mm}$} & " \\
\hline $11 *$ & 우 juv. & 8 & \multicolumn{2}{|r|}{ No large follicle } & Almost none \\
\hline
\end{tabular}

* With Bulsa of Fabricius (In 우 No.11 small non-pneumatic part of the skull) + With incubation patch 
Table 3. Weights of pectoral and leg muscles in one example

\begin{tabular}{|c|c|c|c|c|c|c|c|c|}
\hline \multirow{3}{*}{$\begin{array}{l}\text { Specimen } \\
\text { No. }\end{array}$} & \multicolumn{4}{|c|}{ Pectoralis (One side) } & \multicolumn{3}{|c|}{ Leg muscles (One side) } & \multirow{3}{*}{$\begin{array}{c}\text { Body } \\
\text { weight }\end{array}$} \\
\hline & \multicolumn{3}{|c|}{ P.major } & \multirow{2}{*}{$\left(\begin{array}{l}P . \text { minor } \\
\left(\begin{array}{l}\text { subcorac- } \\
\text { oideus }\end{array}\right)\end{array}\right.$} & \multirow{2}{*}{ Tibial } & \multicolumn{2}{|c|}{ Femoral } & \\
\hline & Proprius & Lateralis & Total & & & Anterior & Posterior & \\
\hline $\begin{array}{l}13 \\
\hat{\delta} 1 \mathrm{st} \\
\text { year }\end{array}$ & $40.1^{g}$ & $15^{\mathrm{g}}$ & $55.1^{\mathrm{g}}$ & $4.2^{\mathrm{g}}$ & $22^{\mathrm{g}}$ & $9.9^{\mathrm{g}}$ & $12.7^{\mathrm{g}}$ & $800^{g}$ \\
\hline \multirow{2}{*}{$\begin{array}{l}96 \text { for } \\
\text { body } \\
\text { weight }\end{array}$} & \multicolumn{3}{|c|}{$6.888 \%$} & $0.525 \%$ & $2.750 \%$ & \multicolumn{2}{|c|}{$2.825 \%$} & \\
\hline & \multicolumn{3}{|c|}{$59.3 \mathrm{~g}$} & & \multicolumn{3}{|c|}{$44.6 \mathrm{~g}$} & \\
\hline
\end{tabular}

* Both sides totals are $14.82 \%$ and $10.16 \%$ of the Body weight

Table 4. Measurements of intestine

\begin{tabular}{|c|c|c|c|c|c|c|c|c|}
\hline \multirow{2}{*}{$\begin{array}{c}\text { Specimen } \\
\text { No. }\end{array}$} & \multirow{2}{*}{ Sex } & \multirow{2}{*}{$\begin{array}{c}\text { Body } \\
\text { weight }\end{array}$} & \multicolumn{3}{|c|}{ Intestine } & \multirow{2}{*}{$\begin{array}{c}\text { Intestine Index } \\
\sqrt[3]{\text { Body W. }} \\
\text { Total int. length }\end{array}$} & \multicolumn{2}{|c|}{ Caeca } \\
\hline & & & Small int. & Rectum & Total & & Left & Right \\
\hline 9 & $\hat{\theta}$ & $800^{g}$ & $\begin{array}{l}\mathrm{mm} \\
860\end{array}$ & $\begin{array}{l}\mathrm{mm} \\
50\end{array}$ & $\begin{array}{c}\mathrm{mm} \\
910\end{array}$ & 0.101 & $\begin{array}{l}\mathrm{mm} \\
15\end{array}$ & $\begin{array}{l}\mathrm{mm} \\
15\end{array}$ \\
\hline 5 & $\hat{\delta}$ & 850 & 910 & 45 & 955 & 0.091 & 15 & 15 \\
\hline 7 & $\hat{\delta}$ & 800 & 860 & - & - & - & 一 & - \\
\hline 10 & $\hat{\delta}$ & 760 & 790 & 50 & 840 & 0.109 & 17 & 17 \\
\hline 13 & $\hat{o}$ & 800 & 810 & 45 & 855 & 0.108 & 17 & 16 \\
\hline 2 & $\hat{\delta}$ & 750 & 800 & 50 & 850 & 0.107 & 18 & 19 \\
\hline \multicolumn{2}{|l|}{ Av. } & 793 & 838.3 & 48 & 882.0 & 0.101 & 16.0 & 16. 4 \\
\hline 1 & 우 & 700 & 870 & 50 & 920 & 0.097 & 15 & 13 \\
\hline 3 & 우 & 750 & 850 & 50 & 900 & 0.101 & 15 & 15 \\
\hline 4 & 우 & 750 & 830 & 50 & 880 & 0.103 & 12 & 15 \\
\hline 6 & 우 & 750 & 880 & 50 & 930 & 0.098 & 18 & 18 \\
\hline 8 & 우 & 750 & 790 & 40 & 830 & 0.109 & 17 & 17 \\
\hline 12 & 우 & 680 & 850 & 50 & 900 & 0.097 & 16 & 14 \\
\hline 11 & 우 & 690 & 870 & 40 & 910 & 0.097 & 15 & 15 \\
\hline \multicolumn{2}{|l|}{ Av. } & 710 & 848.5 & 47 & 895.7 & 0.100 & 15.4 & 15.3 \\
\hline
\end{tabular}

Table 5. Gizzard size and weight (4 examples) and weights of intestine and liver(one example)

\begin{tabular}{|c|c|c|c|c|c|c|c|c|}
\hline \multirow{2}{*}{$\begin{array}{l}\text { Specimen } \\
\text { No. }\end{array}$} & \multirow{2}{*}{$\operatorname{Sex}$} & \multicolumn{2}{|c|}{ Gizzard* } & \multirow{2}{*}{$\begin{array}{c}\text { Intestine } \\
\text { weight }\end{array}$} & \multirow{2}{*}{$\begin{array}{l}\text { Liver } \\
\text { weight }\end{array}$} & \multicolumn{3}{|c|}{$\%$ Body weight } \\
\hline & & Size & Weight & & & Gizzard & Intestine & Liver \\
\hline 11 & 우 & $\begin{array}{c}\mathrm{mm} \\
40 \times 25\end{array}$ & $11.3^{\mathrm{g}}$ & $35.6^{\mathrm{g}}$ & $18.9^{\mathrm{g}}$ & 1.64 & 5.16 & 2.74 \\
\hline 12 & 우 & $31 \times 28$ & 10.6 & - & - & 1.56 & - & - \\
\hline 10 & $\hat{\delta}$ & $38 \times 30$ & 9.2 & - & $\longrightarrow$ & 1.21 & - & $\longrightarrow$ \\
\hline 13 & $\hat{\delta}$ & $38 \times 30$ & 10.8 & - & - & 1.35 & $\ldots$ & $\overline{ }$ \\
\hline \multicolumn{2}{|c|}{ Average } & $38 \times 28$ & 10.5 & - & - & 1.44 & - & $\longrightarrow$ \\
\hline
\end{tabular}

* With some content 
Table 6. Gizzard and intestine contents

\begin{tabular}{|c|c|c|c|}
\hline \multirow{2}{*}{$\begin{array}{l}\text { Specimen } \\
\text { No. }\end{array}$} & \multirow{2}{*}{ Sex } & \multicolumn{2}{|c|}{ Contents of digestive tract (collected before noon) } \\
\hline & & Gizzard & Intestine \\
\hline 9 & $\hat{o}$ & Empty & Not examined \\
\hline 5 & $\hat{\sigma}$ & Cherry stone 1 & Not examined \\
\hline 7 & $\hat{\delta}$ & $\begin{array}{l}\text { Cherry berries } 25 \\
\text { Beetle } 1 \text { (Broken parts and probably } \\
\text { its blue eggs } 40,1 \mathrm{~mm} \text { in diameter) } \\
\text { Hair-like trash. Much }\end{array}$ & Not examined \\
\hline 10 & $\hat{\mathrm{C}}$ & Cherry stones and rind pieces & $\begin{array}{l}\text { Cherry stones } 15 \text { (With some rind) } \\
\text { Cestodes (A bunch at the middle) }\end{array}$ \\
\hline 13 & $\hat{3}$ & $\begin{array}{l}\text { Cherry stones } 18 \\
\text { Apricot rind } 1 \text { piece }(23 \mathrm{~mm} \text { in length) }\end{array}$ & $\begin{array}{l}\text { Cherry stones } 28 \text { (Found along all le- } \\
\text { ngth) } \\
\text { Apricot rind } 3 \text { pieces } \\
\text { Cestodes (Many along all length) }\end{array}$ \\
\hline 2 & 8 & $\begin{array}{l}\text { Skin piece and finger bones of a toad } \\
\text { Beetle } 1 \text { (Broken parts) } \\
\text { A few grey feathers of bird(starling ?) } \\
\text { Some sand }\end{array}$ & Not examined \\
\hline 1 & $\dot{q}$ & $\begin{array}{l}\text { Cherry berries } 3 \\
\text { Cherry stone } 1 \\
\text { Pigeon's eggshell } 3 \text { pieces }\end{array}$ & Not examined \\
\hline 3 & + & $\begin{array}{l}\text { Cherry berries. A few pieces of the } \\
\text { rind }\end{array}$ & Not examined \\
\hline 4 & $\dot{q}$ & Empty & Not examined \\
\hline 6 & F & $\begin{array}{l}\text { A few pieces of tanned hide with some } \\
\text { hair }\end{array}$ & Not examined \\
\hline 8 & f & $\begin{array}{l}\text { Cherry stones } 2 \\
\text { Some animal hair(Chair packing?) } \\
\text { Beetle } 1 \text { (Broken pieces) }\end{array}$ & Not examined \\
\hline 12 & P & $\begin{array}{l}\text { Cherry berries and the stones } 24 \\
\text { (stones 10) } \\
\text { A piece of pigeon's eggshell } \\
\text { A piece of cake }\end{array}$ & $\begin{array}{l}\text { Two bunches of Cestodes, with some } \\
\text { distance, at the middle } \\
\text { No cherries had passed down yet }\end{array}$ \\
\hline 11 & q & Apricot rind pieces 3 & $\begin{array}{l}\text { Small apricot rind pieces } 10 \\
\text { Young Cestodes } 4\end{array}$ \\
\hline
\end{tabular}

後肢筋の量を測った。頭骨の年龄検査はファブリシウス囊をもつ当歳（前年度若鳥）の 1 羽で 行なったところ，非含気性の一部が中央部に残っていた。

生殖器第 2 表の如く, 一般に小さく睾丸は長径 $5 \sim 8 \mathrm{~mm}$, 幅 $3 \sim 5 \mathrm{~mm}$ の長球形でわ 
ずかに休止状態より発達しているにすぎない。これは非繁殖若鳥（多分 2 歳）の生殖器の状態 である。ファブリシウス䨓の残る当藏若鳥と寄生虫からみてやはり若いと思われる他の 1 羽で は，舎丸は $5 \mathrm{~mm} \times 2.5 \mathrm{~mm}$ で細長く，完全休止状態であった。

卵巣も小さく, 長径 $9 \sim 13 \mathrm{~mm}$ で抱卵斑のある早ではまだ $16 \mathrm{~mm}$ あり, 当葴若鳥では $8 \mathrm{~mm}$

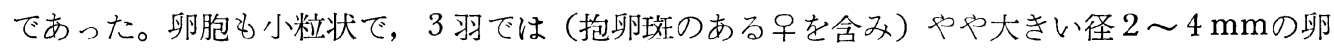
胞 3 個があった。

体脂肪一般に少量かほとんどない状態であったが，ファブリシウス囊の残った若鳥で はかなりの量があった。この個体は胃中にヒキガエル，甲虫，鳥の羽毛などがあり，他の個体 がサクランボなどを多く食べていたのに対し，より肉食嗜好性のようであった。雑食性の鳥で は食物の質と脂肪量に関連があろう。早では個形脂肪少量が腹腔にあるものがあった。

胸筋亡後肢筋量 今回の資料では 1 羽についてのみ検測した (第 3 表)。これによると片側 大胸筋は体重の $6.89 \%$ ，片側小胸筋は $0.53 \%$ ，片側大小胸筋で合計 $7.41 \%$ ，両側合計で 14.82 を占めることとなる。後肢片側全筋量は体重の $5.58 \% ，$ 両側合計で $11.16 \% ，$ 腿部筋は片側で $2.83 \%$ (両肢で $5.66 \%$ )，脛部筋は片側で $2.75 \%$ （両肢て $5.50 \%$ ）を占める。

消化器 4 羽の砂囊（多少の内容共）と若鳥 1 羽についての腸と肝臓重を測定した（第4, 5表)。

小腸は 5 今令の平均838. 3 (790 910) $\mathrm{mm}, 7$ 우우平均848. 5 (790〜880) $\mathrm{mm}$ で恐らく 統計上の差はない。直腸は40〜 $50 \mathrm{~mm}$ であったが，ほぼ $50 \mathrm{~mm}$ である。この小，直腸の合計長

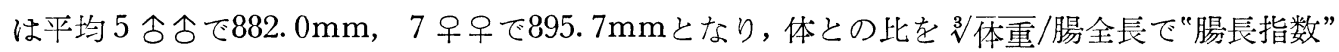
intestine index として求めると，0.091１.109となり合0.101，㝵0.100で差はない。盲腸は 15〜19mmで左右ほぼ等しく, 平均 今 $16 \mathrm{~mm}$, 早 $15 \mathrm{~mm}$ となったが，これも検定は略したが差 はないといえよう。

砂囊の大きさは, 4 羽の平均 $38 \times 28 \mathrm{~mm}, 10.5 \mathrm{~g}$ (多少内容あり) た，体重の $1.2 \sim 1.6$ ( Av 1.4）\%, 腸重は若鳥の 1 例で $35.6 \mathrm{~g}$, 体重の $5.16 \%$, 肝蔵は $18.9 \mathrm{~g}$, 体重の $2.74 \%$ となった。 これらは 1 個体の例で, 統計值が必要である。

消化管内容物 13 羽の砂囊と 4 羽の腸管の内容を調べた（第 6 表）。 8 羽からサクランボ及 びその種子がかなり多くみ出され，最も多い例は砂囊中に18、腸管に28の種子があった（小鳥 では種子は吐出すが，カラスでは腸管に下る)。そのほかは，アンズの果皮，甲虫，個体によ りハトの卵款 1 例, ヒキガエルの皮と足ゆび，小鳥の羽毛数枚，恐らくなめし皮の小片，獣毛

（椅子の詰物らしい），菓子小片が出た。都内での観察によると，ヒキガエルとネズミを捕 食することが多く，早朝残飯から肉片などをあさっている。また冬季には八シボソガラスが渡 来し，それに混り营の島の塵廃棄場が集団採餌の場となる。

腸管寄生虫 消化管内の寄生虫は砂囊にはみられず，腸管を検査した今 2 羽，으 2 羽の例を 第 7 表に示す。目黒寄生虫館の市原醇郎氏の同定によると，次の条虫 2 種であった。

门葉目 Cyclophyllidae

Hymenolepididae

Passerilepis sp. 頭の先の刺は10本

Davaineidae

Raillietina sp. 頭の先の針は50〜60本 


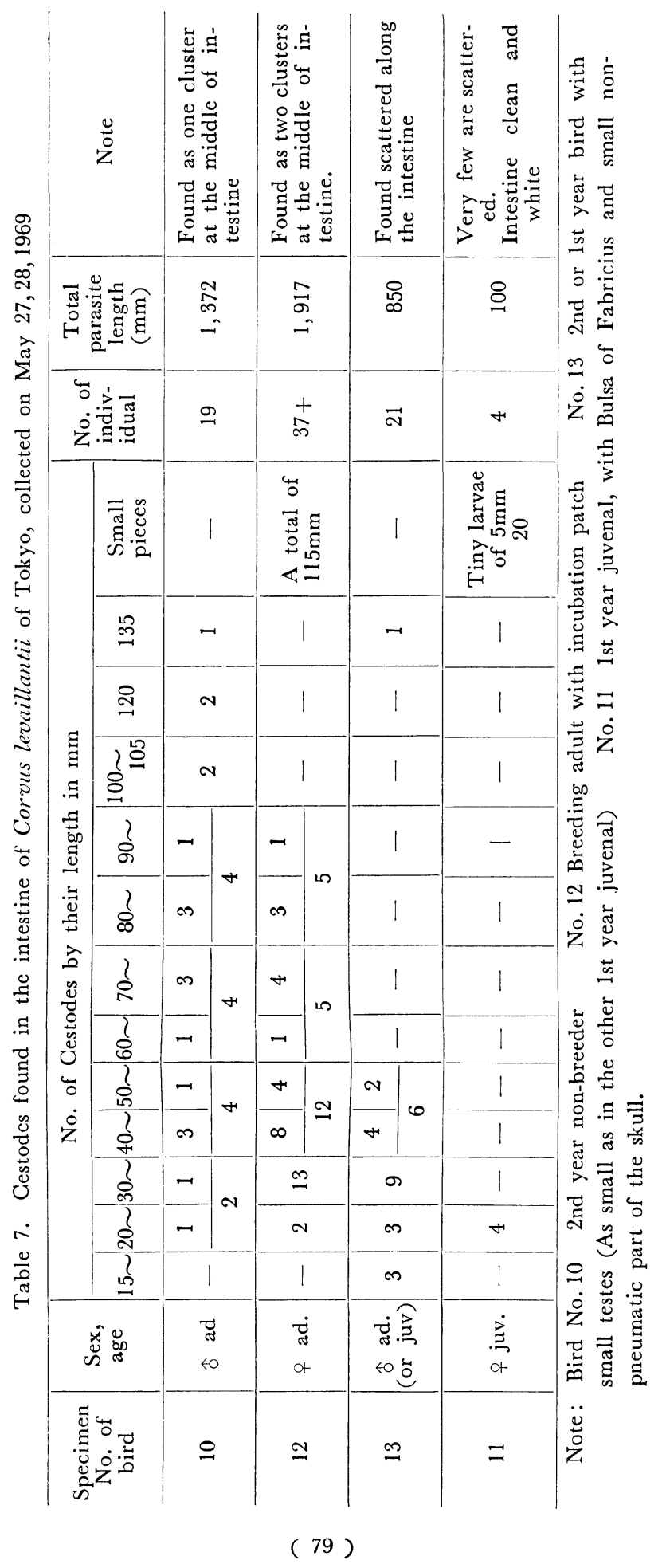


両種は肉眼による区別はほとんどできないので，区別せずにのべる。これらはカラスの年齡 と共に増加していくことがわかった。成虫は $20 \mathrm{~cm}$ までになるといわれるが，発見された最 大は 12 13.5cm であった。個体長は不完全なるのは切片の大きさに従ってつないで推定 し，それでも残ったりのは別にして，寄生虫としての総合計長を出した。

古 No. 11 はファブリシウス霊を残し頭骨含気性孔未完了の若鳥で, ごく小形の $2 \mathrm{~cm}$ まで のもの 4 匹を教えたのみで，寄生虫合計長 $10 \mathrm{~cm}$ にすぎない（ほかに微小な幼生と思われる もの20)。えして腸管は白く血管は少なくきれいで污れがなかった。今 No. 2 もファブリシウ 又孁を有し腸は白くき机いで台った。今 No.13 は寄生虫は腸管の全長にみられたが，個体長 は $5 \mathrm{~cm}$ 内外までで，その合計長は $85 \mathrm{~cm}$ となり，腸管はすでに血管目立ち活れていた。こ の今は生殖器が，他のファブリシウス靈を有する若今と同様に小さく（第 1 表）, 日齢的に若 いものと考えられた。

これに対し非繁殖成鳥と思われる 今No.10 では，腸管の中央の 1 力所に奇生虫が塊りをな していた。その個体長は $12 \sim 13.5 \mathrm{~cm}$ に達し，合計長 $137.2 \mathrm{~cm}$ となった。また，抱卵斑の ある早成鳥 No.12 では, 個体長 $9 \mathrm{~cm}$ まで確認し, ほかに切片合計 $11.5 \mathrm{~cm}$ 分があったから $10 \mathrm{~cm}$ 以上のるのがいたと思われ, 合計長は $191.7 \mathrm{~cm}$ に及んで抢り, 腸管の 2 力所に奇生虫 塊をなしていた。

このように, 若鳥ては寄生虫は少なく腸はきれいで, 年齢と共に増え腸管が污れてくる。こ の寄生虫の増殖が, 雑食性に関連してどこまで進み, それがカラスの死亡率や寿命にどう作用 するか， Iつの問題として考えられよう。

なお，郊外の耕地のカラスには鈎頭虫の寄生が多いとのことであるが，それが今回の都内の ハシブトガラスでみられなかったことは，都内個体群としての留鳥性を反映していると思う。 一方ハシボソガラスは冬烏として都内に大きな群で郊外から侵入してくるのである。

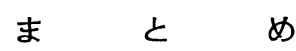

1969年 5 月に皇居内で採集されたハシブトガラス13羽について諸検測を行なっだ。

1. 無作意採集に上る性比は 6 今令, 웅であった。そのうち占㝵各 1 羽はファブリシウス 囊が残る当歳，他は主に非繁殖の若鳥（二歳）と思われ，1 古は抱卵斑のある成鳥であった。

2. 体重抢よび外部諸検測值の平均はすべてっで古り大きく, その比を性差指数 sexual index S.I. \%で示し（今>早を正，今<早は負とする), その意義についてのべた。S.I.は体

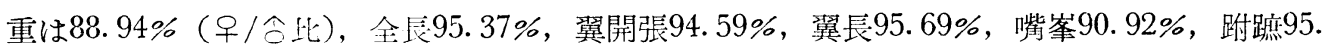
$54 \%$ ，尾長 $98.33 \%$ ミ亦った。

3. 内部検測は，次のようであった。

a. 生殖器は一般に非生殖状態にあった。

b. 体脂肪は一般に添とんどないかごく少量であった。

c. 䏩筋は左右大小胸筋合計（別々に検測）で体重の $14.82 \%$, 後肢筋量は脛部左右合計 で体重の5.50\%，腿部筋量は $5.66 \%$ あった。

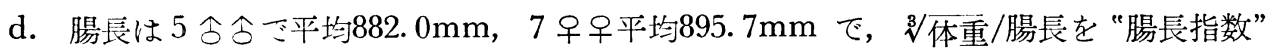
intestine index 乞して計算し今0.101，午0.100でほとんど差はなかった。盲腸は平均、16 
$\mathrm{mm}$, 우 $15 \mathrm{~m}$ で左右ほぼ同じであった。砂震は 4 例平均 $38 \times 28 \mathrm{~mm}, 10.5 \mathrm{~g}$ で体重の $14 \%$. 肝臓は 1 例で体重の $2.74 \%$ あった。

e. 砂露および腸管内容物は, この季節にはサクランボが最も多くみ出され，アンズの皮， 甲出，八トの卵殼，ヒキガエルの皮と足，小鳥の羽毛，獣毛（製品らしい），菒子片などがあ った。観察ではネズミもよく捕食する。

f. 腸内寄生虫は Cyclophyllidae の条虫の Passerilepis 属と Raillietina 属の 2 種で若 鳥には少なく腸はきれいで, 成鳥ほど多くなり腸の中間部に虫塊でみられた。寄生虫量は個体 垃と虫の総合計長で示した。若鳥では $10 \mathrm{~cm}$ にすぎず， $85 \mathrm{~cm}, 137.2 \mathrm{~cm}, 191.7 \mathrm{~cm}$ の変化が あった。な技，東京郊外のカラスに多いという鈎頭虫は発見されず，この点から都内に留鳥で 㐫ることを示した。

\section{Measurements, stomach contents and intestinal parasites in 13 Jungle Crows obtained in Tokyo Nagahisa Kuroda}

Thirteen examples of Corvus levaillantii japonensis obtained in Tokyo, May 27, 28, 1969, were measured, and examined anatomically.

1. Sex ratio was even, being $6 \hat{o} \hat{o}, 7$ 우 우, and one of the each sex retained Bulsa of Fabricius (the famale example examined still showed a small non-pneumatic part of the skull). These, and perhaps one other male, were young of the previous year. Others were probably non-breeding 2nd year subadults, having little developed gonads in this season(Least developed in the above young of the year). One of the famale was a breeding adult having incubation patch.

2. They had little or almost no fat, except one young male which ate more animal food.

3. Body weight and all external measurements were larger in the male, and this difference was expressed by 'sexual index', S.I. which is : smaller measurement/larger measurement $\not 6$ (positive value in $\hat{\delta}>\rho$, and negative in $\hat{o}<\%$ ), and its significance was discussed. This index ranged 88. 94\% (Body weight) 98.33\%(Tail 1.) and all were positive.

4. In one example, the total pectoralis was $14.82 \%$ of body weight, the femoral muscles $5.66 \%$ and tibial $5.50 \%$.

5. Length of intestine was average $882.0 \mathrm{~mm}$ in $5 \hat{\delta} \hat{\delta}, 895.7 \mathrm{~mm}$ in 7 우 우 and 'intestine in-

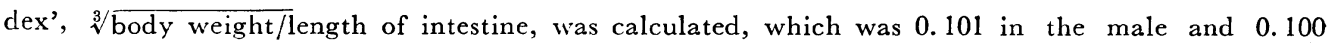
in the femal. The caeca were $15-16 \mathrm{~mm}$. The gizzard was av. $38 \times 28 \mathrm{~mm}$ in size and $10.5 \mathrm{~g}(1.4 \%$ of body weight) and the liver in one example was $2.74 \%$ of body weight.

6. Most gizzard and intestine (4 examples examined) contained cherry berries (their stones) with other items such as toad's part, beetles, pigeon eggshell, bird feathers and animal hairs (probably chair material) or cake piece, etc. In observation toad and rat are favored food items beside human food debris.

7. Two species of Cestodes, Passerilepis sp. and Raillietina sp. were found in all of four intestines examined (not 'found in the gizzard) and the numbers were counted by individual length and by its sum, i.e. : the 'total parasite length'. Younger bird(with Bulsa of Fabricius) had total parasite length of only $10 \mathrm{~cm}$ and the intestine was clean, while others had from $85 \mathrm{~cm}$ (scattered along the intestine wall), $137.2 \mathrm{~cm}$ (clustered at the middle) to $191.7 \mathrm{~cm}$ (found as two clusters) in an adult female with incubation patch. The individual length was also increasingly longer.

8. The parasite's number and total parasite length thus increase with the age of the bird and this might affect the bird's longevity or mortality. The Acanthocephala usually to be found in suburban crows (possibly C. corone) was not found and this reflects that C. levaillantii in Tokyo is permanent resident within the city zone.

Yamashina Inst. for Ornithology, (150), Nanpeidai 8-20, Shibuya, Tokyo. 